Marquette University

e-Publications@Marquette

Chemistry Faculty Research and Publications

Chemistry, Department of

$1-1-2002$

\title{
Polystyrene/Graphite Nanocomposites: Effect on Thermal Stability
}

Fawn Marie Uhl

Marquette University

Charles A. Wilkie

Marquette University, charles.wilkie@marquette.edu

Accepted version. Polymer Degradation and Stability, Vol. 76, No. 1 (2002): 111-122. DOI. (C) 2002 Elsevier B.V. Used with permission. 


\title{
Marquette University
}

\section{e-Publications@Marquette}

\section{Chemistry Faculty Research and Publications/College of Arts and Sciences}

This paper is NOT THE PUBLISHED VERSION; but the author's final, peer-reviewed manuscript. The published version may be accessed by following the link in th citation below.

Polymer Degradation and Stability, Vol. 76, No. 1 (2002): 111-122. DOI. This article is (C) Elsevier and permission has been granted for this version to appear in e-Publications@Marquette. Elsevier does not grant permission for this article to be further copied/distributed or hosted elsewhere without the express permission from Elsevier.

\section{Polystyrene/graphite Nanocomposites: Effect on Thermal Stability}

\author{
Fawn M. Uhl \\ Department of Chemistry, Marquette University, PO Box 1881, Milwaukee, WI \\ Charles A. Wilkie \\ Department of Chemistry, Marquette University, PO Box 1881, Milwaukee, WI
}

\begin{abstract}
Nanocomposites consisting of polymer and clay have been shown to exhibit a significant reduction in flammability and an increase in mechanical properties. This work examines the effect of thermal stability and mechanical properties of nanocomposites prepared from potassium graphite and styrene. Synthesis of nanocomposites was accomplished by using potassium graphite $\left(\mathrm{KC}_{8}\right)$ as the initiator in the polymerization of styrene. A slight increase in thermal stability is observed but mechanical properties are decreased.
\end{abstract}

Keywords

Nanocomposites, Polystyrene, Graphite, Thermal stability, Cone calorimetry, Potassium graphite

\section{Introduction}

Polymer-clay nanocomposites have been shown to exhibit a significant increase in thermal stability and an enhancement in mechanical properties ${ }^{[1]}$. The dispersion of the clay within the polymer has a most significant 
influence on the properties of the material. When the clay is not well-dispersed, no nanocomposite is formed; if it is well-dispersed, either an intercalated or a delaminated nanocomposite is formed. Intercalated nanocomposites consists of well-ordered layers in which registry is maintained between the clay layers while this registry is lost in delaminated, also known as exfoliated, nanocomposites. The formation of delaminated nanocomposites seems to lead to a greater enhancement of mechanical properties than is observed for intercalated systems. It has been suggested that layered materials may be beneficial to the enhancement of polymer properties.

Graphite is another layered material and it is thought that an enhancement in properties may be observed. Nyden and Gilman have performed molecular dynamic simulations (MD_REACT) for nanocomposites composed of graphite and polypropylene ${ }^{[2]}$. They found that the "nanocomposite effect" of this system is best when the graphite layers are separated by $\sim 3.0 \mathrm{~nm}$.

Nyden and Gilman have also observed that for a polyamide-6/clay nanocomposite, there is a critical mass fraction value that can not be exceeded to form intercalated structures, once this value is exceeded the nanocomposite becomes delaminated. For intercalated nanocomposites the attractive forces must be stronger than the repulsive forces, otherwise the clay structure will become delaminated and form a hybrid structure. It has been shown that intercalated compounds are more thermally stable than the delaminated nanocomposites ${ }^{[3]}$. Based on these observations, it would be assumed that there should be an increase in thermal stability observed for the graphite-polymer nanocomposites.

The graphite structure consists of carbon layers in an alternating stacking sequence. The carbon atoms are bonded covalently in a hexagonal arrangement within the layer and these layers are weakly bonded to each other. It is the weak van der Waals forces between the layers which makes intercalation possible. The typical dspacing between the carbon layers in graphite is approximately 3.35 $\AA$. Graphite is known to form lamellar compounds with alkali metals, where the carbon has taken on a planar arrangement ${ }^{[4], ~[5], ~[6] . ~ P o t a s s i u m ~ c a n ~}$ insert into the graphite structure to give a number of compounds, called stages. The first stage material, $\mathrm{KC}_{8}$, has an orthorhombic orientation and the d-spacing increases from $3.35 \AA$ for graphite to $5.41 \AA$ for $K C_{8}$. Second stage, $\mathrm{KC}_{24}$, has a spacing of $8.72 \AA$, while the third stage material, $K C_{36}$, has a spacing of $12.1 \AA$.

Shioyama has shown that graphite intercalation compounds (GIC) of alkali metals can form ternary compounds with organic molecules [7], [8], [9], [10]. Shioyama's work showed that unsaturated hydrocarbons could be cointercalated into the graphite layers of alkali metal-GICs. Once the hydrocarbon was intercalated, polymerization could be carried out in the interlayer spacing of graphite. The polymerizations were done using metal-GIC compounds ( $\mathrm{RbC}_{24}, \mathrm{CsC}_{24}, \mathrm{KC}_{24}$, and $\mathrm{KC}_{8}$ ) with the vapor of isoprene, 1,3-butadiene, and styrene. Shioyama observed expansion of the graphite layers within "several tens of minutes" ${ }^{[7]}$. In the case of $\mathrm{KC}_{24}$ and $\mathrm{KC}_{8}$, polymerized samples resembled exfoliated graphite but lacked a characteristic "gap" and the bulk density of the samples was similar to that of the virgin polymer ${ }^{[7],[8]}$. X-ray diffraction of the polymers show no peaks due to graphite or the GIC; this is attributed to the layers being separated and disordered due to the polymerization. Thermogravimetric analysis results were similar to the virgin polymers. Reactions of $\mathrm{KC}_{8}$ and $\mathrm{KC}_{24}$ with acrylonitrile, 1-butene, and isobutene were also examined. It was found that these polymers could react for more than a month and no expansion of the GIC was detected ${ }^{[9]}$. X-ray diffraction patterns showed the coexistence of stages 2 and 3 potassium-GICs and no other phases were observed ${ }^{[9]}$. It was also found that $\mathrm{KC}_{24^{-}}$ polymer (acrylonitrile, 1-butene, isobutene) was stable in water for up to 11 days upon which the potassium-GIC decomposed to a stage 4 compound; this indicates high stability of these systems ${ }^{[9]}$. This is thought to be due to monomers polymerizing only on the surface of the GIC edge, which would protect the GIC in water ${ }^{[9]}$. For the polymers prepared using $\mathrm{RbC}_{24}$ and $\mathrm{CsC}_{24}$, similar results are observed where the products resemble exfoliated graphite, but the bulk density and thermal properties are similar to those of the commercial polymers ${ }^{[10]}$. X-ray diffraction patterns of $\mathrm{RbC}_{24}$-polymers show only peaks resembling those of the commercial polymer while 
thermogravimetric analysis of these polymers is also similar to the commercial polymer ${ }^{[10]}$. The $\mathrm{CsC}_{24}-$ polymer systems show peaks in the X-ray diffraction of polymer and additional peaks attributed to higher stage Cs-GICs; suggesting that polymerization is low ${ }^{[10]}$.

In this work the bulk polymerization of styrene using potassium graphite, $\mathrm{KC}_{8}$, as the initiator has been examined. Previous work has been carried out using this initiator but, in most cases, the polymer has been washed free of the graphite so it is unknown if a nanocomposite had been formed. Based upon the simulations of Nyden and Gilman, one may anticipate enhanced thermal stability for the nanocomposites.

\section{Experimental}

\subsection{Materials}

All materials were obtained from Aldrich Chemical Company. The graphite was in the form of a powder of 1-2 $\mu \mathrm{m}$ size. The styrene was used after removal of the inhibitor (4-tert-butylcatechol) by passing the monomer through an inhibitor-remover column, followed by distillation. Commercial polystyrene (Aldrich) of 280,000 molecular weight was used to prepare blends and as a reference material. $\mathrm{KC}_{8}$ was prepared following literature methods [7], [8], [9], [10], [11].

\subsection{Analysis}

A Cahn TG-131 thermoanalyzer was used under a flowing inert atmosphere at a scan rate of $20^{\circ} \mathrm{C}$ min. Samples were cut from the graphite/polymer nanocomposite. The temperature at which $10 \%$ degradation occurs is taken as representative of the onset temperatures of degradation. $T_{\max }$ is the temperature at which the maximum rate of degradation occurs and is another measure of thermal stability. All TGA results are the average of at least three runs; typically the temperatures are reproducible to $\pm 3{ }^{\circ} \mathrm{C}$. Cone calorimetry was performed per ASTM E 1354-92 using a Stanton Redcroft/PL Thermal Sciences instrument at $35 \mathrm{KW} / \mathrm{m}^{2}$ in the horizontal orientation. The samples were $6.3 \mathrm{~mm}$ and mounted using the edge retainer frame and wire grid; the mass was approximately $35 \mathrm{~g}$. Exhaust flow was set at $24 \mathrm{l} / \mathrm{s}$ and the spark was continuous until the sample ignited. Infrared spectra were obtained using a Nicolet Magna infrared 560 spectrometer E.S.P. ${ }^{1} \mathrm{H}$ Nuclear magnetic resonance spectroscopy was performed on a General Electric QE 300 NMR in deuterated chloroform at 300 $\mathrm{MHz}$. X-ray diffraction (XRD) was performed on a Rigaku Geiger Flex, 2-circle powder difractometer using CuK $\alpha$ radiation. Scans were taken from 2 theta at $0.70-30^{\circ}$, step size $0.1^{\circ}$, and scan time per step of $20 \mathrm{~s}$.

\subsection{Preparation of potassium graphite initiator $\left(\mathrm{KC}_{8}\right)$}

The preparation of the initiator followed the literature procedures [11], [12], [13], [14], [15]. A 250-ml, 3-neck round bottom flask, glass stirring rod, dropping funnel, and nitrogen inlet/outlet was oven-dried overnight, then assembled and flame dried with a Bunsen burner under a nitrogen atmosphere. To the cooled glassware was added graphite and this was flame dried with a Bunsen burner. The flask and its contents were heated to $120{ }^{\circ} \mathrm{C}$, and potassium was added over approximately a $30 \mathrm{~min}$ period with vigorous mechanical stirring. Upon completion of addition the mixture was allowed to stir an additional $2 \mathrm{~h}$. The resulting product was small yellow balls with a light brown coating and a reflective coating had formed on the surface of the flask. The material was used immediately as a polymerization catalyst.

\subsection{Polymerization of styrene intercalated with graphite, method I-all graphite as initiator}

The polymerization was performed by the addition of styrene to the flask containing the initiator. In a typical reaction, a flask containing the $\mathrm{KC}_{8}(3.66 \mathrm{~g})$ was cooled to $0{ }^{\circ} \mathrm{C}$; to the chilled flask was added, through an addition funnel, $77.0 \mathrm{ml}(70.0 \mathrm{~g})$ of purified styrene over $30 \mathrm{~min}$. The Reaction proceeded rapidly. The reaction flask was left overnight, under nitrogen, to permit the completion of the reaction. The flask and its contents 
were then exposed to air for $24 \mathrm{~h}$ and the polymer was removed from the flask by heating, followed by annealing for $24 \mathrm{~h}$ at $120^{\circ} \mathrm{C}$. The reaction products of the potassium, presumably the oxide, hydroxide and carbonate, formed from the reaction of the metal with oxygen, water, and carbon dioxide in air, were not removed.

\subsection{Polymerization of styrene intercalated with graphite, method II- addition of graphite during bulk polymerization}

The polymerization was performed similar to method I, but using a smaller amount of initiator and adding additional graphite during the polymerization. In a typical reaction, a flask containing the $\mathrm{KC}_{8}(1.07 \mathrm{~g})$ was cooled to $0{ }^{\circ} \mathrm{C}$; to the chilled flask was added, through an addition funnel, $88.0 \mathrm{ml}(80.0 \mathrm{~g})$ of purified styrene over 30 min and $1.76 \mathrm{~g}$ graphite was added in one portion. The reaction proceeded more slowly than for the method above. The reaction flask was left overnight, under nitrogen, to permit the completion of the reaction. The flask and its contents were then exposed to air for $24 \mathrm{~h}$ and the polymer was removed from the flask by heating, followed by annealing for $24 \mathrm{~h}$ at $120^{\circ} \mathrm{C}$.

\subsection{Polymerization of styrene intercalated with graphite, method III-addition of graphite after bulk polymerization}

The polymerization was performed similar to method I. In a typical reaction, a flask containing the $\mathrm{KC}_{8}(1.47 \mathrm{~g})$ was cooled to $0{ }^{\circ} \mathrm{C}$; to the chilled flask was added, through an addition funnel, $100.0 \mathrm{ml}(90.9 \mathrm{~g})$ of purified styrene over $30 \mathrm{~min}$. The reaction flask was left overnight, under nitrogen, to permit the completion of the reaction. The flask and its contents were then exposed to air for $24 \mathrm{~h}$ and the polymer was removed from the flask by heating. Upon removal from flask the polymer was blended (using a Brabender mixer) with additional $2.57 \mathrm{~g}$ of graphite. This sample was annealed for $24 \mathrm{~h}$ at $120^{\circ} \mathrm{C}$.

\subsection{Preparation of polystyrene using potassium as initiator}

The polymerization was performed by the addition of styrene to the flask containing potassium. In a typical reaction, to a flask containing potassium $(0.43 \mathrm{~g})$ was added, through an addition funnel, $60.0 \mathrm{ml}(54.5 \mathrm{~g})$ of purified styrene over $30 \mathrm{~min}$. Reaction proceeded slowly and was allowed to react for 6 days. Then methanol $(150 \mathrm{ml})$ was added and mixture exposed to air for several days to allow any unreacted potassium to be consumed. Polymer was removed and dried in a vacuum oven at $100{ }^{\circ} \mathrm{C}$ over night.

\subsection{Preparation of polystyrene/graphite blends}

Blends were prepared using a Brabender Plasticorder mixer. The mixer was heated to $220^{\circ} \mathrm{C}$ and commercial polystyrene $(\mathrm{Mw}=\mathbf{2 8 0}, 000)$ and graphite were poured into blender and allowed to mix for $20 \mathrm{~min}$. After the polymer was removed from the Brabender, it was annealed overnight under vacuum at $120^{\circ} \mathrm{C}$. Blends were prepared containing 2 and $5 \%$ graphite.

\subsection{Extraction of polymer}

Polymers were extracted from the nanocomposites using THF; typically solvent was poured onto the nanocomposite and allowed to sit for $24 \mathrm{~h}$. The polymer was filtered through Celite to remove graphite and precipitated with methanol. In a typical example $1 \mathrm{~g}$ of graphite-containing polystyrene was placed in $200 \mathrm{ml}$ of THF and precipitated with $400 \mathrm{ml}$ of methanol. Infrared spectra of the extracted polymer showed the absence of graphite, peaks typically observed at 1600 and $1360 \mathrm{~cm}^{-1}$ are no longer present.

\subsection{Determination of molecular weight}

Molecular weight determinations were performed using a Ubbelohde viscometer in a water bath maintained at $30.0 \pm 0.2^{\circ} \mathrm{C}$. Samples were prepared by dissolving $0.25 \mathrm{~g}$ of extracted polystyrene in $25 \mathrm{ml}$ of toluene. Into the 
viscometer was placed $10 \mathrm{ml}$ of solution and allowed to come to equilibrium at $30.0^{\circ} \mathrm{C}$. Then the solution was drawn into the observation bulb and allowed to drain and time was recorded. This was repeated three times and the average value used. In this case [ $\eta$ ] was calculated using the Huggins equation for single point viscosity determination. The kh (Huggins constant) for the anionic polymerization of styrene in toluene is $0.51{ }^{[16]}$.

\section{Results and discussion}

\subsection{Preparation of initiator and polymerization}

The preparation of the initiator is a well-known procedure, first introduced by Lancette ${ }^{[17],[18]}$. Since the first stage compound, $\mathrm{KC}_{8}$, is a golden color, it is easy to observe that the preparation was successful. The polymerization was performed using three different techniques for the introduction of graphite into the material. In the first method, all of the graphite was introduced in the form of the initiator. There were two sources of graphite for the other two methods of preparation, the initiator along with the addition of additional graphite. These were used in order to investigate materials with variable amounts of graphite. In the second method, the additional graphite was added during the polymerization while for the third method, additional graphite was added through a melt blending process, post reaction, using a Brabender mixer. It must be noted that the reaction products of potassium, likely the oxide, hydroxide and carbonate, were not removed and may be present in the nanocomposite. The presence of additional graphite during the preparation slows the reaction, however there is little, if any, effect on the molecular weight between the various preparative methods. The molecular weight data will be discussed in a later section of this paper.

\subsection{X-ray diffraction}

The typical d-spacing for graphite is $3.35 \AA$ and upon conversion to $K C_{8}$, this expands to $5.41 \AA$. Fig. 1 shows typical plots for graphite and polystyrene; the d001 peak for graphite can be seen at $2 \vartheta=13.35^{\circ}$. The broad features near $2 \vartheta=10$ and $18^{\circ}$ that are apparent in polystyrene are observed in all polystyrene nanocomposites that have been prepared in this laboratory and are attributed to the polymeric phase [19]. Fig. 2 shows the XRD plots for graphite blended with commercially available polystyrene. The XRD of the blends showed no change in $\mathrm{d}$-spacing from that observed in graphite; there is no intercalation through melt blending in this system. This is validated by the observation of peaks for graphite, $2 \vartheta=13.35$ and $26.55^{\circ}$, and polystyrene, $2 \vartheta=10$ and $18^{\circ}$, present without change in position. Fig. 3, Fig. 4, Fig. 5 show the plots for nanocomposites prepared by methods $\mathrm{I}$, II and III, respectively. In these plots two theta is 5.85 and, using Bragg's law ( $\lambda=2 \mathrm{~d} \sin \vartheta)$, the $\mathrm{d}$-spacing increases to $15.1 \AA$. In some instances the spacing is somewhat larger, up to $22.3 \AA$. From the XRD one can see that intercalated nanocomposites are formed by all three methods. Definitive proof of the formation of a nanocomposite typically requires transmission electron microscopy (TEM) in addition to XRD data; attempts to obtain TEM results for these nanocomposites have been unsuccessful. 

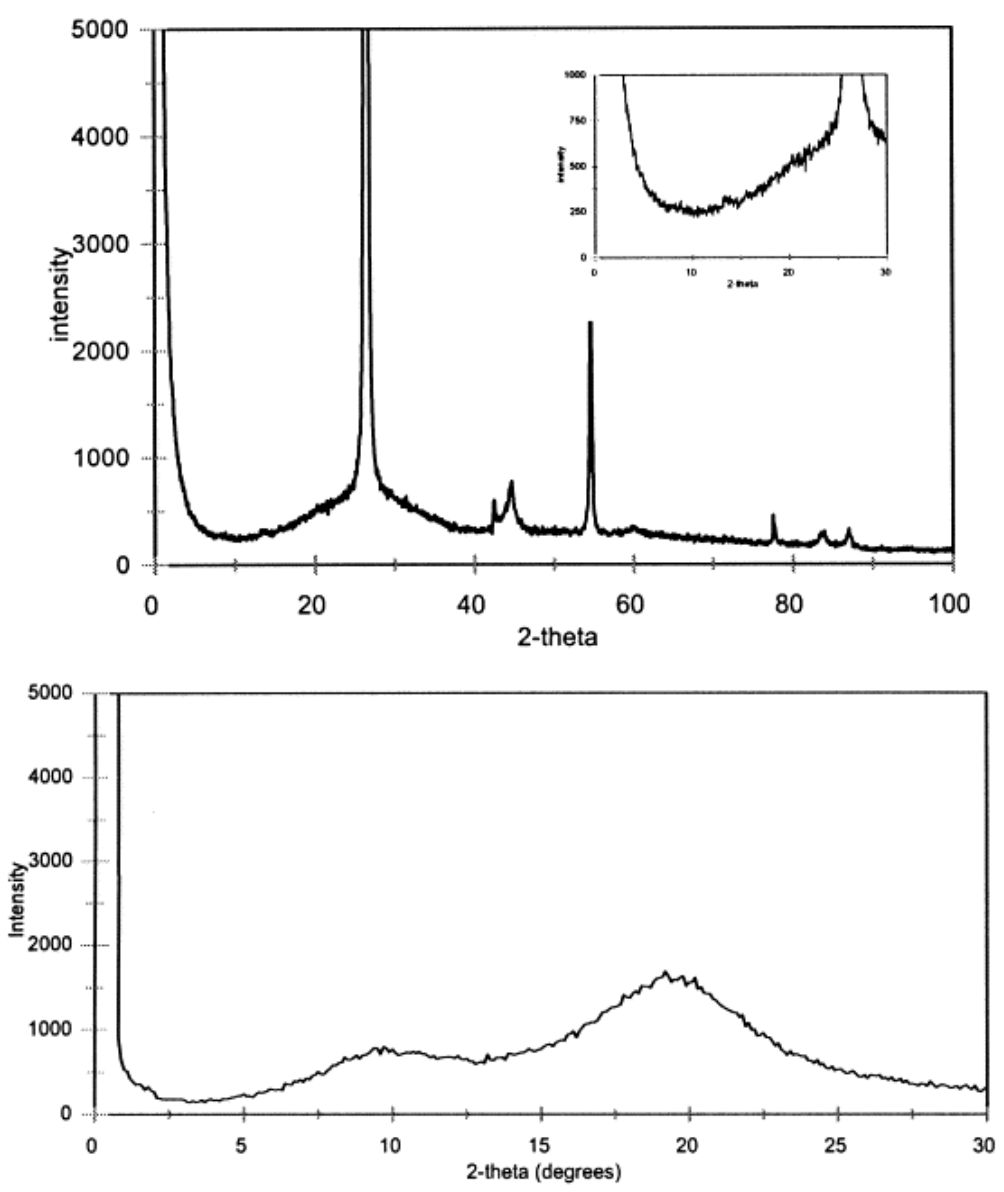

Fig. 1. X-ray diffraction patterns of graphite (top) and ploystyrene (bottom). Inset is of expanded region between 2-theta angles 0 and 30.
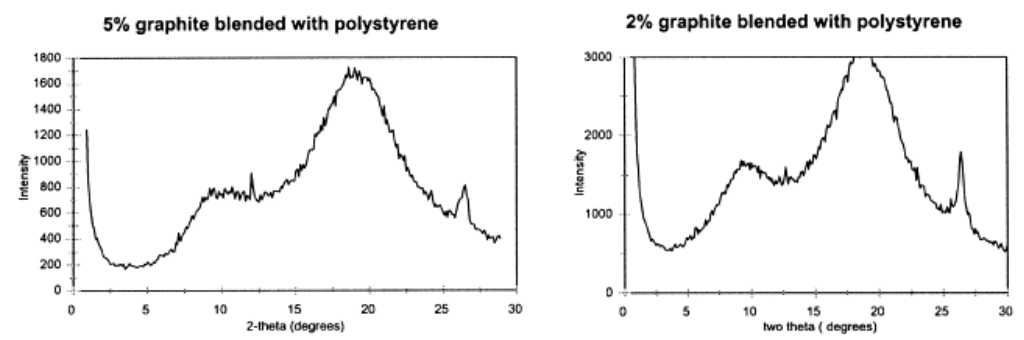

Fig. 2. XRD plots of blends. 

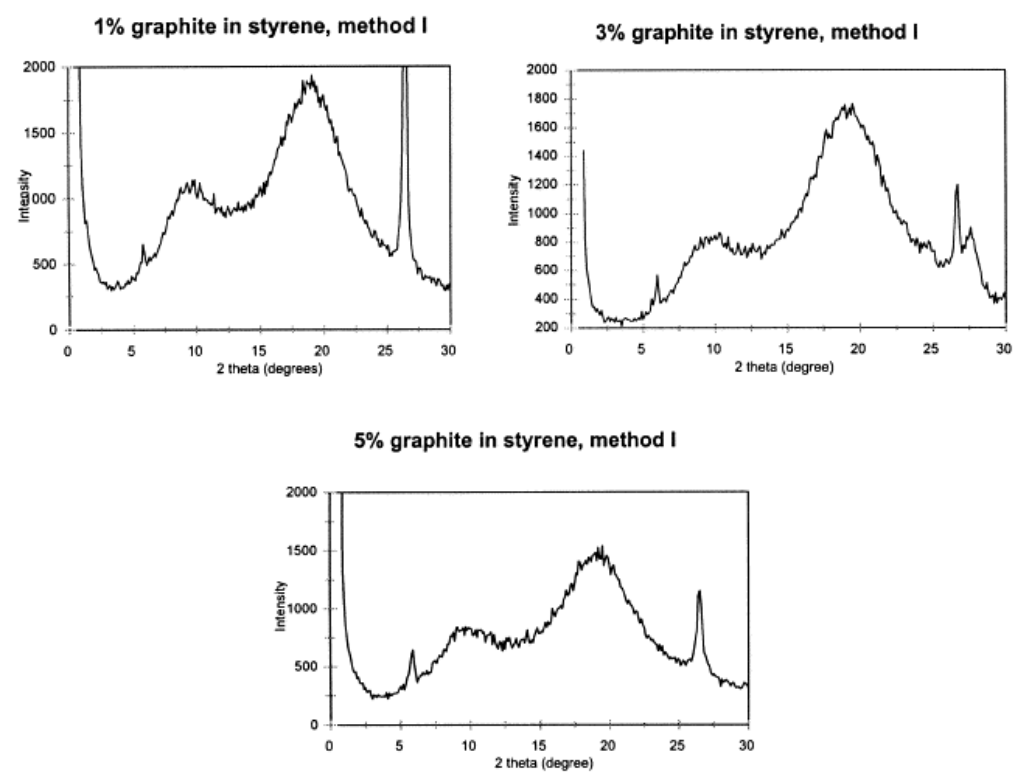

Fig. 3. XRD plots of nanocomposites prepared by method I.
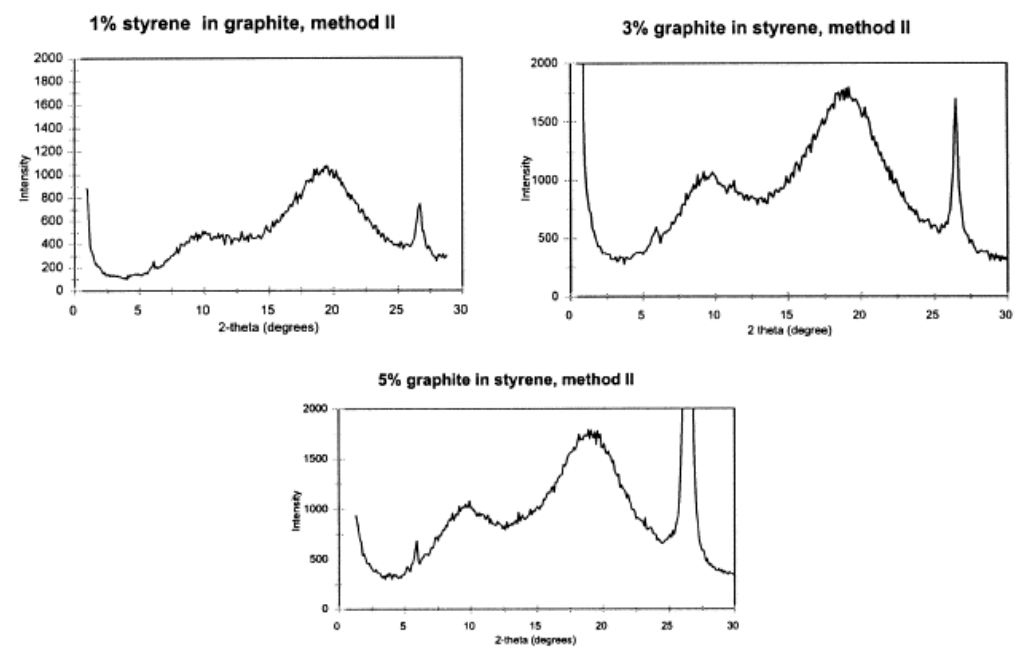

Fig. 4. XRD plots of nanocomposites prepared by method II.
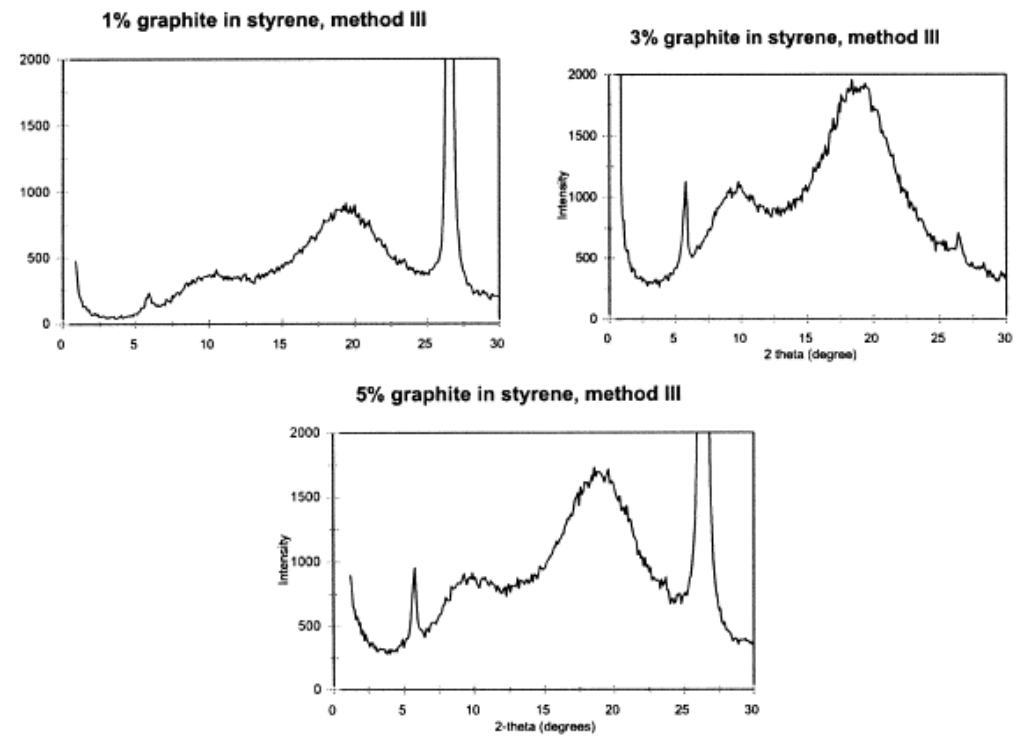

Fig. 5. XRD plots of nanocomposites prepared by method III. 


\subsection{Thermogravimetric analysis of the nanocomposites and blends}

Thermogravimetric analysis data, which is presented in Table 1, shows the onset temperature of the degradation, as measured by the temperature at which $10 \%$ degradation occurs, the maximum peak in the derivative, $T_{\max }$, as an indicator of the course of the degradation, and the fraction of non-volatile material which remains at $600{ }^{\circ} \mathrm{C}$, char. The onset temperature of degradation for the polystyrene/graphite nanocomposites increases by about $50{ }^{\circ} \mathrm{C}$ compared to commercial polystyrene and similar results are obtained for $T_{\max }$; these are quite similar to the values that have been previously reported for polystyrene-clay nanocomposites. The polystyrene prepared using potassium as the initiator shows a slightly lower onset of degradation while $T_{\max }$, is consistent, except in the case of method III where the values are higher. There is not much difference between the three methods of preparation but a slight enhancement is seen for systems in which not all of the graphite was added in the form of $\mathrm{KC}_{8}$. In all cases the reaction products of potassium are present, of course, the amount depends upon the amount of initiator that was used; the amount of initiator has little effect on thermal stability so it must be concluded that the presence of these reaction products do not influence the thermal stability. A large amount of material which is non-volatile at elevated temperature, in many cases significantly more than the amount of graphite that was added, is found in many TGA experiments. The amount of non-volatile does not show any significant variation based on either the mode of preparation or the amount of initiator so it is unlikely to be significantly influenced by the presence of potassium salts. There is also some variability in the amount of char and this must be attributable to sampling problems, which suggests that these nanocomposites are not uniform. It is of interest to note that the materials in which additional graphite has been added post reaction show much more consistent results.

Table 1. Thermogravimetric analysis of graphite-polystyrene nanocomposites prepared by all methods; com. is virgin polystyrene produced commercially of 280,000 molecular weight

\begin{tabular}{|c|c|c|c|c|}
\hline$\% \mathrm{KC}_{8}$ & $\% \mathrm{C}$ & $T_{10 \%}\left({ }^{\circ} \mathrm{C}\right)$ & $T_{\max }\left({ }^{\circ} \mathrm{C}\right)$ & Char (\%) \\
\hline \multicolumn{5}{|c|}{ Method I-all graphite from initiator } \\
\hline 0 & & 394 & 436 & $1 \pm 1$ \\
\hline Com. & & 351 & 418 & 0 \\
\hline 5.04 & 3.59 & 419 & 446 & $19 \pm 10$ \\
\hline 5.12 & 3.67 & 401 & 442 & $7 \pm 2$ \\
\hline 4.17 & 2.95 & 417 & 445 & $9 \pm 3$ \\
\hline 4.17 & 2.96 & 415 & 445 & $10 \pm 2$ \\
\hline 3.14 & 2.19 & 410 & 443 & $19 \pm 4$ \\
\hline 3.39 & 2.41 & 410 & 441 & $11 \pm 3$ \\
\hline 2.13 & 1.51 & 406 & 442 & $8 \pm 1$ \\
\hline 1.10 & 0.779 & 419 & 445 & $9 \pm 2$ \\
\hline 1.39 & 0.987 & 408 & 444 & $6 \pm 1$ \\
\hline \multicolumn{5}{|c|}{ Method II-additional graphite added during polymerization } \\
\hline 1.89 & 5.35 & 442 & 451 & $30 \pm 8$ \\
\hline 1.91 & 5.18 & 416 & 444 & $25 \pm 19$ \\
\hline 1.32 & 4.31 & 428 & 453 & $26 \pm 1$ \\
\hline 1.41 & 3.96 & 425 & 448 & $29 \pm 5$ \\
\hline 2.23 & 3.17 & 411 & 451 & $15 \pm 12$ \\
\hline 1.85 & 3.08 & 402 & 439 & $22 \pm 1$ \\
\hline 2.21 & 2.15 & 418 & 448 & $9 \pm 2$ \\
\hline 1.20 & 1.18 & 420 & 453 & $9 \pm 2$ \\
\hline 1.5 & 1.3 & 410 & 457 & $5 \pm 1$ \\
\hline 1.20 & 1.18 & 416 & 448 & $7 \pm 4$ \\
\hline
\end{tabular}




\begin{tabular}{|l|l|l|l|l|}
\hline Method III-additional graphite added post reaction & & & & \\
\hline 1.9 & 5.53 & 428 & 455 & $12 \pm 1$ \\
\hline 1.6 & 4.90 & 431 & 451 & $11 \pm 1$ \\
\hline 1.70 & 3.67 & 426 & 457 & $13 \pm 2$ \\
\hline 1.80 & 3.00 & 428 & 452 & $6 \pm 1$ \\
\hline 1.24 & 1.15 & 419 & 468 & $7 \pm 1$ \\
\hline 1.62 & 0.969 & 428 & 447 & $5 \pm 1$ \\
\hline
\end{tabular}

The graphite containing polymers were extracted and the extracted materials examined by TGA (Table 2). It is surprising that the extracted polymers show very similar onset temperatures of degradation as observed for the polystyrene-graphite nanocomposites; but upon examination of polystyrene prepared using only potassium the values are as expected. The procedure that was used to remove the graphite will also eliminate any potassium salts so these extracted polymers are pure materials. An even greater surprise is the observation of significant non-volatile residue from the reaction. The fraction of non-volatile residue does, in general, decrease but it does not go to zero as one might have expected. One logical explanation for the enhanced thermal stability and the presence of non-volatile residue is the incomplete removal of graphite from the polymer. Indeed when the nanocomposites were filtered through filter paper, the presence of graphite was obvious from the color of the dried polymer. Filtration through a Celite filter bed allows the complete removal of graphite and this is shown in the infrared spectra by the absence of the peaks due to graphite in the 1500 and $1000 \mathrm{~cm}^{-1}$ regions (Fig. 6); the absence of potassium salts is also shown through the lack of anion vibrations in the IR spectra. Peaks corresponding to the graphitic structure in carbon black are typically observed at 1600 and $1360 \mathrm{~cm}^{-1}$ [20]. The uncertainties in the amount of non-volatile are the values that one may expect in a typical TGA run and give credence to the absence of either graphite or potassium salts. NMR spectroscopic measurements have been carried out on the extracted polymers and they appear to be completely atatic materials; the apparent higher thermal stability cannot be due to tacticity differences. A possible explanation may be a memory effect, similar to what has been described by Blumstein.

Table 2. Thermogravimetric analysis of the extracted polymer

\begin{tabular}{|c|c|c|c|c|c|}
\hline$\% \mathrm{KC}_{8}$ & $\% \mathrm{C}$ & $T_{10 \%}\left({ }^{\circ} \mathrm{C}\right)$ & $T_{\text {max }}\left({ }^{\circ} \mathrm{C}\right)$ & $\begin{array}{c}\text { Char } \\
(\%)\end{array}$ & $\begin{array}{l}\text { Mol. wt. } \\
\text { (g/mol) }\end{array}$ \\
\hline \multicolumn{6}{|c|}{ Method I-all graphite from initiator } \\
\hline 5.04 & 3.59 & 409 & 438 & $2 \pm 1$ & $1.7 \times 10^{5}$ \\
\hline 5.45 & 3.67 & 412 & 444 & $7 \pm 1$ & $6.1 \times 10^{5}$ \\
\hline 4.17 & 2.95 & 418 & 440 & $4 \pm 1$ & $7.5 \times 10^{5}$ \\
\hline 4.17 & 2.96 & 420 & 442 & $4 \pm 1$ & $7.1 \times 10^{5}$ \\
\hline 3.14 & 2.19 & 408 & 441 & $5 \pm 1$ & $3.2 \times 10^{5}$ \\
\hline 3.39 & 2.41 & 402 & 438 & $2 \pm 1$ & $2.4 \times 10^{5}$ \\
\hline 2.13 & 1.51 & 418 & 445 & $4 \pm 1$ & $4.4 \times 10^{5}$ \\
\hline 1.10 & 0.779 & 419 & 443 & $5 \pm 1$ & $5.0 \times 10^{5}$ \\
\hline 1.09 & 0.987 & 395 & 440 & $4 \pm 1$ & $2.8 \times 10^{5}$ \\
\hline \multicolumn{6}{|c|}{$\begin{array}{l}\text { Method II-additional graphite added during } \\
\text { polymerization }\end{array}$} \\
\hline 1.89 & 5.35 & 413 & 442 & $3 \pm 1$ & $3.3 \times 10^{5}$ \\
\hline 1.91 & 5.18 & 406 & 447 & $1 \pm 1$ & $4.6 \times 10^{5}$ \\
\hline 1.32 & 4.31 & 412 & 449 & $2 \pm 1$ & $4.3 \times 10^{5}$ \\
\hline 1.41 & 3.96 & 395 & 434 & $4 \pm 1$ & $8.2 \times 10^{5}$ \\
\hline 2.23 & 3.17 & 413 & 441 & $3 \pm 2$ & $6.7 \times 10^{5}$ \\
\hline 1.85 & 3.08 & 397 & 451 & $2 \pm 1$ & $6.7 \times 10^{5}$ \\
\hline
\end{tabular}




\begin{tabular}{|l|l|l|l|l|l|}
\hline 2.21 & 2.15 & 414 & 446 & $4 \pm 1$ & $2.0 \times 10^{5}$ \\
\hline 1.20 & 1.18 & 396 & 443 & $2 \pm 1$ & $8.4 \times 10^{5}$ \\
\hline 1.5 & 1.3 & 407 & 442 & $3 \pm 2$ & $7.6 \times 10^{5}$ \\
\hline 1.20 & 1.18 & 385 & 442 & $1 \pm 1$ & $11 \times 10^{5}$ \\
\hline Method III-Additional graphite added post reaction & & & & & \\
\hline 1.9 & 5.53 & 423 & 449 & $2 \pm 1$ & $18 \times 10^{5}$ \\
\hline 1.6 & 4.90 & 415 & 445 & $1 \pm 1$ & $28 \times 10^{5}$ \\
\hline 1.70 & 3.67 & 391 & 445 & $2 \pm 1$ & $7.5 \times 10^{5}$ \\
\hline 1.80 & 3.00 & 391 & 436 & $4 \pm 1$ & $7.7 \times 10^{5}$ \\
\hline 1.24 & 1.15 & 421 & 448 & $2 \pm 1$ & $14 \times 10^{5}$ \\
\hline 1.62 & 1.27 & 427 & 451 & $1 \pm 1$ & $6.6 \times 10^{5}$ \\
\hline
\end{tabular}

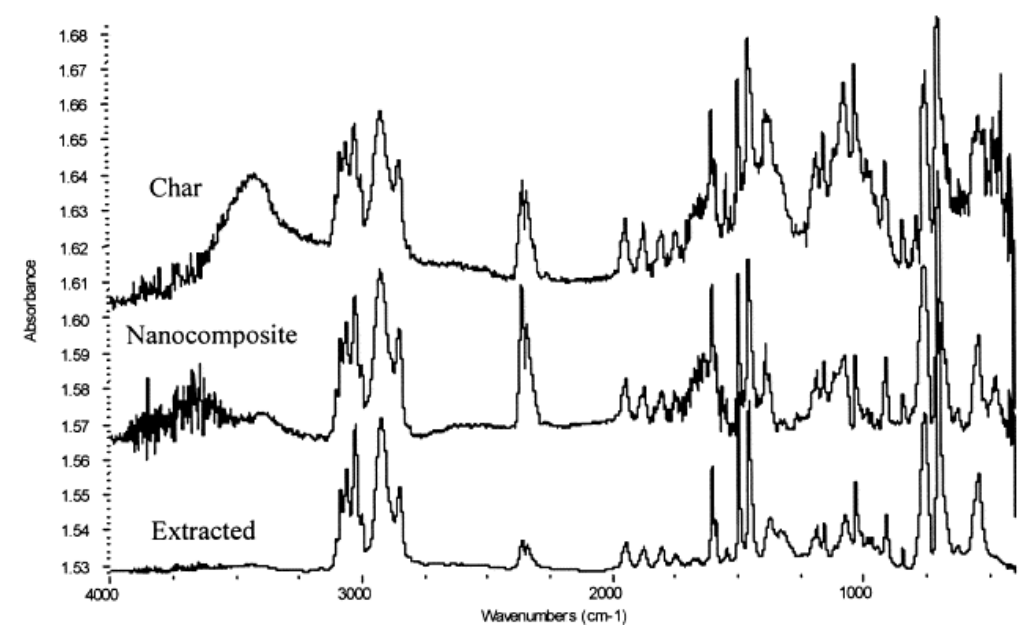

Fig. 6. Infrared spectra of extracted polystyrene (bottom), graphite/polystyrene nanocomposite (middle), and char of nanocomposite at $600^{\circ} \mathrm{C}$ (top).

Blumstein has studied the polymerization of methyl methacrylate by adsorption onto montmorillonite clay [21], [22], [23], [24], [25], [26]. He observed that as monomer is adsorbed onto the surface there is an oriented growth of the polymer which results in a polymer that still possesses the memory of the monomer-substrate interactions and organization within the adsorbed layers. This was seen in the architecture and stereospecifity of the polymer. The polymer retained within the clay did not degrade under conditions where poly(methyl methacrylate) does undergo thermal degradation. When the polymer was extracted from the clay, it was observed to have a higher thermal stability than bulk polymerized poly(methyl methacrylate). It was suggested that the insertion polymer and the crystalline surface on which polymerization occurred may be replicas, i.e., the internally trapped monomer polymerizes replicating the surfaces on which it is adsorbed. This can be seen in the specificity of the polymer versus what would be expected. He suggests that isotatic triads were formed due to the templating effect of the clay cations. Therefore, the way in which a polymer is prepared will affect its properties, leading to what is called a "memory effect".

Viscosity measurements have been performed on the extracted polymers to determine the molecular weight of polystyrene (Table 2). The viscometric molecular weights range from $1 \times 10^{5}$ to over $1 \times 10^{6} \mathrm{~g} / \mathrm{mol}$. This molecular weight is consistent with what has been previously reported for polymers initiated by potassium graphite and with the molecular weight determined for polystyrene prepared with potassium $\left(5.2 \times 10^{5} \mathrm{~g} / \mathrm{mol}\right)$. There does not appear to be any correlation between the amount of initiator and the molecular weight of the polymer.

Thermogravimetric analysis of the blends prepared with the Brabender mixer have similar onset temperatures of degradation and char formation (amount of non-volatile residue remaining in TGA pan) to those prepared by 
method I (Table 3). The onset temperature is a little higher for the nanocomposite than for the blends but there is not a large difference. From XRD measurements, these blends do not show any expansion of the d-spacing of graphite so nanocomposites are not formed in the blending process. Perhaps the microdispersion in the blends offers the same barrier properties as observed in the nanocomposites with graphite. Very good dispersion of the clay is essential to obtain good thermal properties but this may not be essential for graphite.

Table 3. TGA data for blends

\begin{tabular}{|l|l|l|l|}
\hline$\% \mathrm{C}$ & $\mathrm{T} 10 \%\left({ }^{\circ} \mathrm{C}\right)$ & $T_{\max }\left({ }^{\circ} \mathrm{C}\right)$ & Char $(\%)$ \\
\hline 5.0 & 397 & 439 & $8 \pm 1$ \\
\hline 4.8 & 407 & 444 & $9 \pm 1$ \\
\hline 2.1 & 402 & 438 & $9 \pm 1$ \\
\hline 2.0 & 402 & 439 & $7 \pm 1$ \\
\hline
\end{tabular}

The TGA curves for representative nanocomposites prepared by all three methods are shown in Fig. 7 while the curves for a blend and a nanocomposite prepared in which all of the graphite comes from the initiator are shown in Fig. 8.

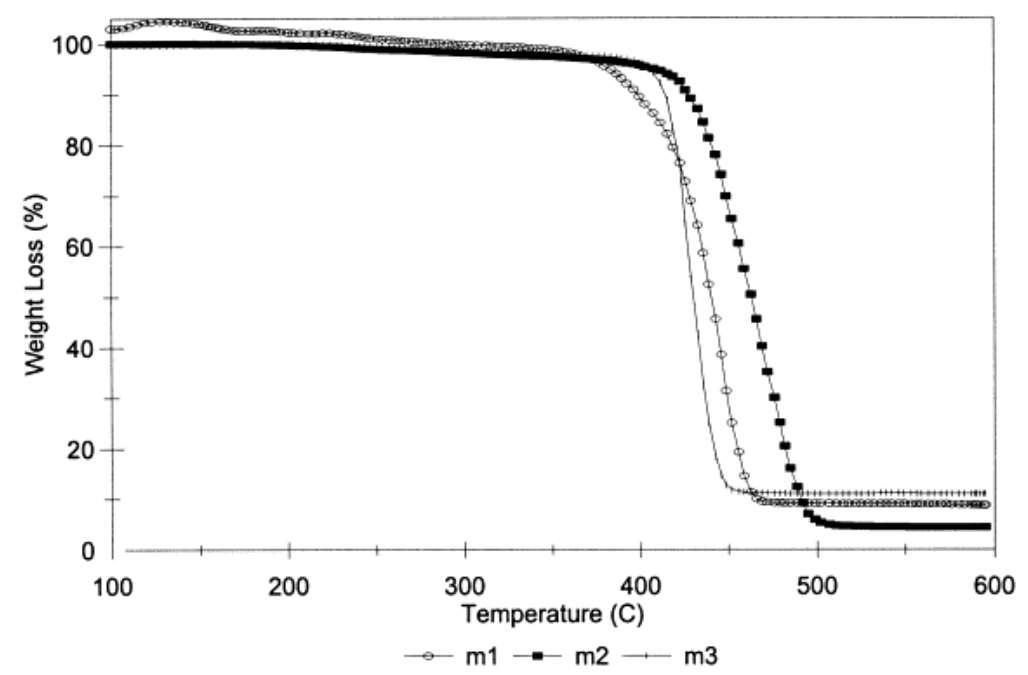

Fig. 7. TGA curves for polystrrene-graphite nanocomposites prepared by all three methods; the legends refers to the methods of preparation.

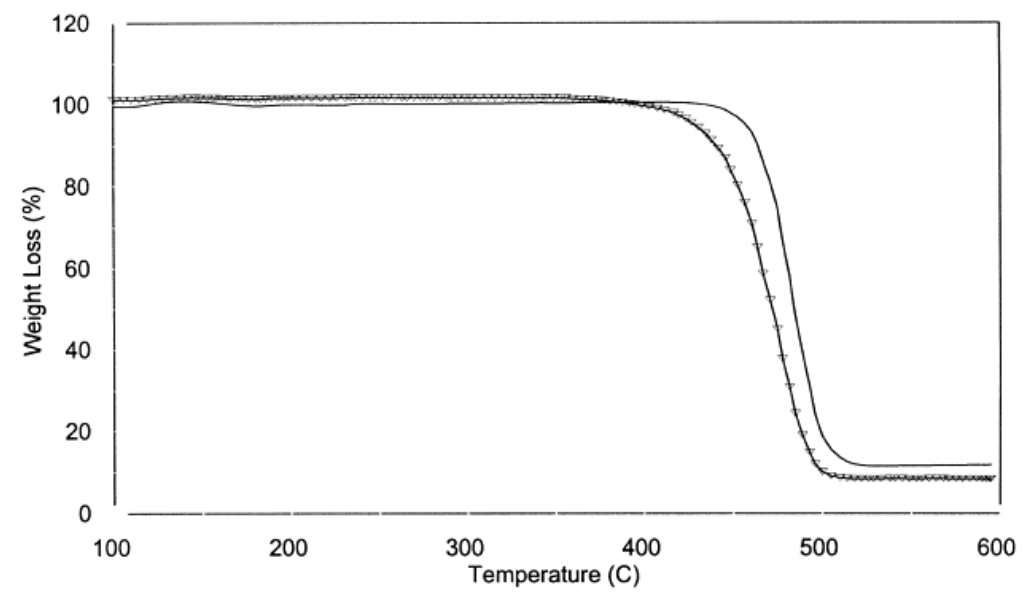

Fig. 8. Thermogravimetric analysis of blend $(\nabla)$ and nanocomposite $(-)$. 
In comparing the methods of preparation, it is clear that the nanocomposite prepared by the addition of graphite during the polymerization has a slightly higher onset temperature and $T_{\max }$ than do the other preparative modes.

\subsection{Cone calorimetry of the nanocomposites and blends}

The graphite containing polymers were examined by Cone calorimetry and the results are shown in Table 4. From this data, one can see that the peak heat release rate, PHRR, for the graphite-containing polystyrene nanocomposites is lower than that of the virgin polystyrene, typically about $35 \%$ lower. The increased time to burnout and an overall decrease in mass loss and mass loss rate suggest that the graphite is acting to slow down the thermal degradation of the polystyrene. The specific extinction area (SEA, a measure of smoke produced) of the graphite-containing polymers is lower than for the virgin polymer. From these results, it appears that the graphite does introduce some stability to the polymer. The typical error in Cone measurements is $\pm 10 \%$, based upon thousands of measurements ${ }^{[27]}$. The uncertainties reported in the tables of Cone data are within the typical range, indicating that these much larger samples avoid the sampling problem noted from the TGA data. For polystyrene-clay nanocomposites, the reduction in peak heat release rate, at the 3 and $5 \%$ clay level is about $50 \%$ so these graphite systems do not offer the same reduction as in the clay nanocomposites.

Table 4. Cone calorimetry results for nanocomposites

\begin{tabular}{|c|c|c|c|c|c|c|c|}
\hline$\% \mathrm{KC}_{8}$ & $\begin{array}{l}t_{\text {ignition }} \\
(\mathrm{s})\end{array}$ & $\begin{array}{l}\text { tPHRR } \\
\text { (s)a }\end{array}$ & $\begin{array}{l}\mathrm{PHRR}^{\mathrm{a}} \\
\left(\mathrm{kW} / \mathrm{m}^{2}\right)\end{array}$ & $\begin{array}{l}\text { Mean HRR a } \\
\left(\mathrm{kW} / \mathrm{m}^{2}\right)\end{array}$ & $\begin{array}{l}\text { Avg. SEA }{ }^{a} \\
\left(\mathrm{~m}^{2} / \mathrm{kg}\right)\end{array}$ & $\begin{array}{l}\text { Mass loss } \\
\%\end{array}$ & $\begin{array}{l}\text { Mass loss } \\
\text { rate }(\mathrm{mg} / \mathrm{s})\end{array}$ \\
\hline \multicolumn{8}{|c|}{$\begin{array}{l}\text { Method I-all graphite from } \\
\text { initiator }\end{array}$} \\
\hline PS & 35 & 165 & 1024 & 479 & 1572 & 86.0 & 127 \\
\hline 5.08 & $33 \pm 4$ & $197 \pm 0$ & $635 \pm 14$ & $332 \pm 10$ & $1193 \pm 133$ & $80.0 \pm 2.5$ & $107 \pm 1$ \\
\hline 4.17 & $25 \pm 0$ & $190 \pm 17$ & $670 \pm 36$ & $352 \pm 10$ & $976 \pm 36$ & $82.7 \pm 1.8$ & $114 \pm 6$ \\
\hline 3.26 & $30 \pm 7$ & $181 \pm 3$ & $665 \pm 13$ & $352 \pm 19$ & $1034 \pm 26$ & $84.9 \pm 2.6$ & $108 \pm 1$ \\
\hline 1.10 & $28 \pm 11$ & $183 \pm 0$ & $668 \pm 20$ & $376 \pm 15$ & $1009 \pm 18$ & $82.5 \pm 3.1$ & $110 \pm 1$ \\
\hline \multicolumn{8}{|c|}{$\begin{array}{l}\text { Method II-additional } \\
\text { graphic added during } \\
\text { polymerization }\end{array}$} \\
\hline 1 & $30 \pm 7$ & $169 \pm 0$ & $579 \pm 29$ & $308 \pm 34$ & $815 \pm 111$ & $80.7 \pm 4.4$ & $98 \pm 2$ \\
\hline 3 & $22 \pm 10$ & $170 \pm 2$ & $669 \pm 47$ & $308 \pm 19$ & $906 \pm 34$ & $84.2 \pm 2$ & $119 \pm 3$ \\
\hline 5 & $22 \pm 3$ & $175 \pm 8$ & $710 \pm 25$ & $449 \pm 34$ & $1033 \pm 13$ & $84.2 \pm 2.1$ & $118 \pm 2$ \\
\hline \multicolumn{8}{|c|}{$\begin{array}{l}\text { Method III-additional } \\
\text { graphite added post } \\
\text { reaction }\end{array}$} \\
\hline 1 & $22 \pm 10$ & $187 \pm 12$ & $682 \pm 30$ & $352 \pm 24$ & $1006 \pm 20$ & $87.2 \pm 8.8$ & $115 \pm 8$ \\
\hline 3 & $22 \pm 10$ & $182 \pm 8$ & $657 \pm 30$ & $332 \pm 34$ & $927 \pm 63$ & $85.5 \pm 0.1$ & $119 \pm 2$ \\
\hline 5 & $8 \pm 3$ & $169 \pm 27$ & $657 \pm 41$ & $332 \pm 34$ & $908 \pm 90$ & $81.6 \pm 3.2$ & $113 \pm 4$ \\
\hline
\end{tabular}

at $_{\text {ignition, }}$ Time to ignition; $t_{P H R R}$, time to peak heat release rate; PHRR, peak heat release rate; Mean HRR, mean heat release rate; SEA, specific extinction area (a measure of the amount of smoke relased).

The heat release rate for the blends (Table 5) is slightly higher than that of those prepared by method I, but, still significantly lower than that of virgin polystyrene. Also observed is a slightly higher mass loss for the blends than for method I, suggesting that the polymers prepared by method I may have somewhat higher stability. 
Table 5. Cone calorimetry data for the blends

\begin{tabular}{|l|l|l|l|l|l|l|l|}
\hline$\% K C_{8}$ & $\begin{array}{l}\% \\
\mathrm{C}\end{array}$ & $\begin{array}{l}\mathrm{t}_{\text {gnnition }} \\
(\mathrm{s})^{\mathrm{a}}\end{array}$ & $\begin{array}{l}\mathrm{t}_{\text {PHRR }} \\
(\mathrm{s})^{\mathrm{a}}\end{array}$ & $\operatorname{PHRR}^{\mathrm{a}}\left(\mathrm{kW} / \mathrm{m}^{2}\right)$ & Mean HRR $\left(\mathrm{kW} / \mathrm{m}^{2}\right)$ & Avg. SEA ${ }^{\mathrm{a}}\left(\mathrm{m}^{2} / \mathrm{kg}\right)$ & Mass loss (\%) \\
\hline PS & & 35 & 165 & 1024 & 479 & 1572 & 86 \\
\hline Blends & 5 & 35 & 190 & 702 & 381 & 1008 & 84 \\
\hline & 4.8 & 30 & 182 & 727 & 342 & 918 & 84 \\
\hline & 2.1 & 30 & 178 & 693 & 352 & 950 & 85 \\
\hline & 2.0 & 30 & 167 & 762 & 361 & 974 & 87 \\
\hline
\end{tabular}

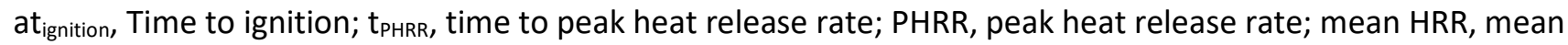
heat release rate; SEA, specific extinction area (a measure of the amount of smoke released).

The heat release rate data is presented in graphical form for all modes of preparation and blends in Fig. 9. For all systems the peak heat release rate is reduced, but not as much as seen in the typical polystyrene-clay nanocomposite ${ }^{[19]}$. It is of interest to note that the shape of the peaks is quite different for these materials when compared to polystyrene-clay nanocomposites. For the clay systems, the heat release rate curve raises very quickly and stays at a somewhat high level for most of the time. On the other hand, in these graphite systems the curve rises slowly and this can be seen by the reduction in the mean heat release rate.

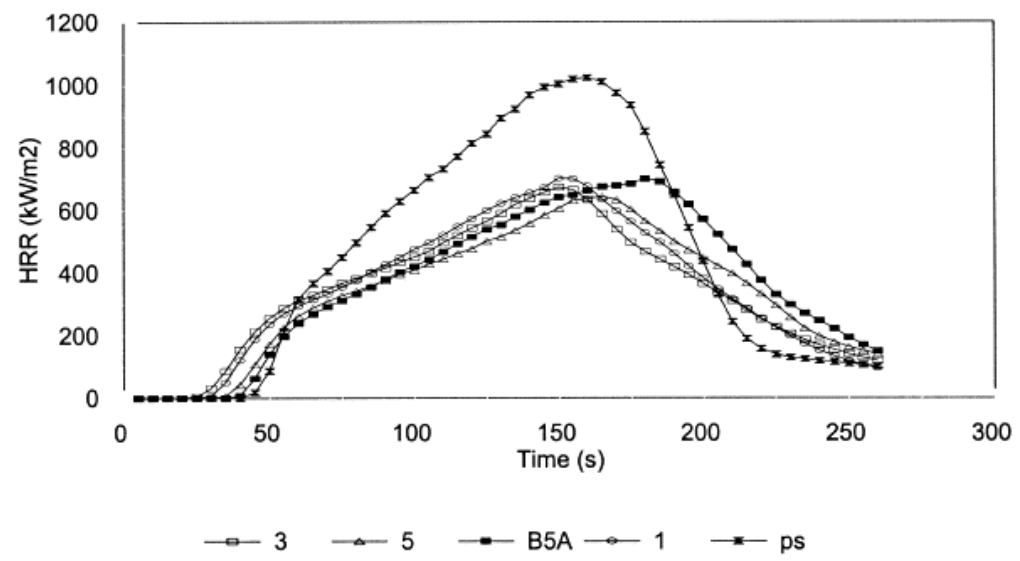

Fig. 9. Heat release rate curves for nanocomposites and blends compared to virgin polystyrene. Samples 1,3 , and 5 refer to nanocomposites containing that amount of graphite while sample B5A is a blend containing $5 \%$ graphite.

\subsection{Mechanical properties}

The mechanical properties of clay-polymer nanocomposites are increased relative to that of the virgin polymer, and this is especially true for exfoliated materials. In work from this laboratory, we have observed a $300 \%$ increase in strength at break along with a $45 \%$ increase in elongation at break for an exfoliated clay nanocomposite. An intercalated polystyrene-clay nanocomposite gives $120 \%$ increase in strength at break with no change in elongation at break ${ }^{[28]}$. Fig. 10, Fig. 11 display the elasticity modulus and tensile strength, respectively, as a function of the amount of graphite for all methods of preparation compared to commercial polystyrene. The tensile strength and elasticity modulus are lower for the nanocomposites compared to commercial polystyrene. As the amount of graphite increases, there is a decrease in mechanical properties. Increasing the amount of graphite appears to help the thermal stability, but it detracts from the performance of the polymer. 


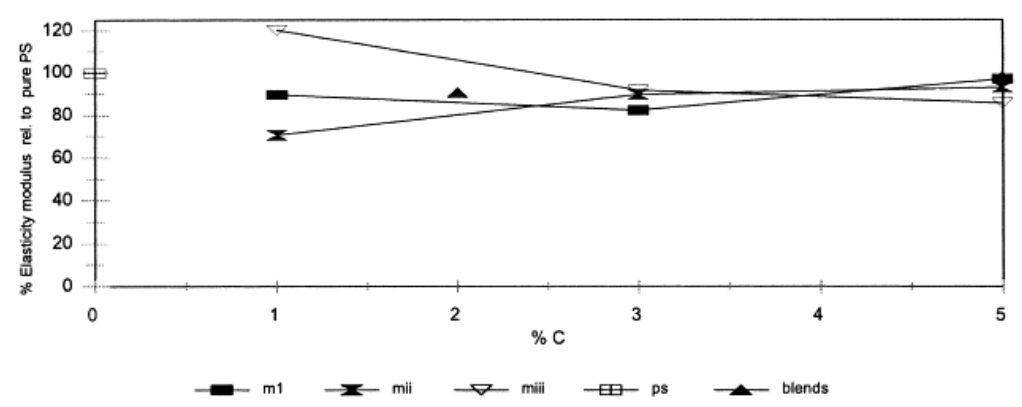

Fig. 10. Elasticity modulus as a percentage compared to commercial polystyrene.

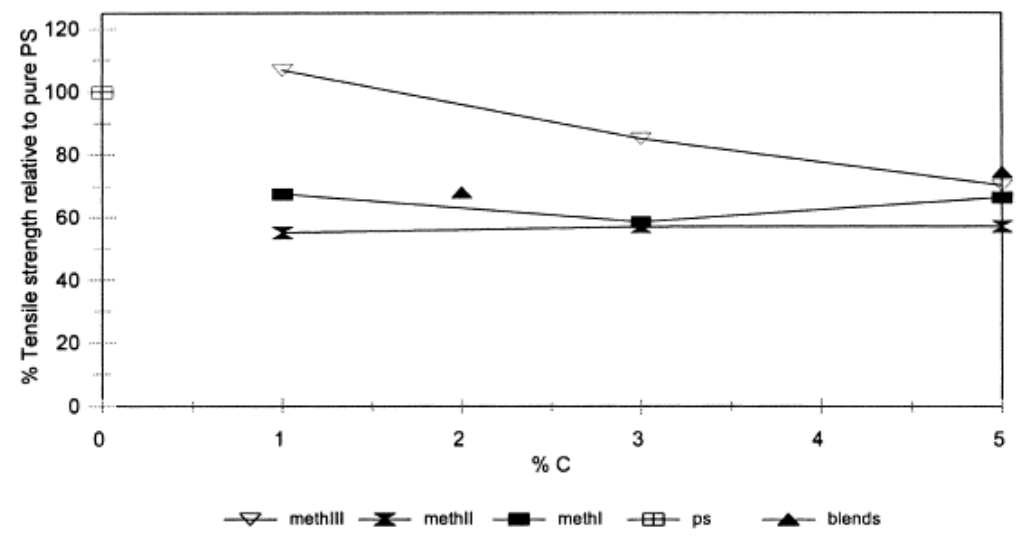

Fig. 11. Tensile strength as a percentage compared to commercial polystyrene.

\section{Conclusions}

Polymers of very high molecular weight are produced when potassium graphite is used as an initiator. Nanocomposites may be prepared in which all of the carbon comes from the initiator or by the addition of graphite after the reaction has commenced. There is a larger effect on thermal stability when additional graphite is added. The thermal stability, as measured by TGA, is slightly better for nanocomposites than for blends and the same is also true of fire properties, as measured by Cone calorimetry. Gilman and Nyden have stated that the "nanocomposite effect" is best when the graphite layers are separated by about $3 \mathrm{~nm}{ }^{[2]}$.

The separation in this study, has been only one-half of this value. Our results show that intercalated nanocomposites have been formed and an increase in thermal stability is observed; this is in accord with work done by Nyden and Gilman, where an increase in thermal properties should be observed for intercalated structures. The use of clay nanocomposites as fire retardants is unique in the fact that not only is an enhancement in thermal properties observed but also an increase in mechanical properties. Unfortunately a decrease in mechanical properties is observed for these nanocomposites. Further work will attempt to increase the spacing to see if this has an effect.

\section{Acknowledgements}

The work was performed under the sponsorship of the US Department of Commerce, National Institute of Standards and Technology, Grant Number 70NANBOH0096. The assistance of Marcel van den Berk and David Paul, Solutia, Inc., in obtaining the Cone calorimetry data is appreciated.

\section{References}

[1] M Alexandre, P Dubois. Mater. Sci. Eng., R28 (2000), p. 1

[2] M.R Nyden, J.W Gilman. Comp. Theor. Polym. Sci., 7 (1997), p. 191 
[3] Gilman JW, Kashiwagi T. In: Pinnavaia TJ, Beall GW, editors. Polymer-clay nanocomposites. New York: John Wiley \& Sons; 2000. p. 193-205.

[4] G.R Hennig. Prog. Inorg. Chem., 1 (1959), p. 125

[5] W Rudorff. Adv. Inorg. Radiochem, 1 (1959), p. 223

[6] H Selig, L.B Ebert. Adv Inorg. Radiochem., 23 (1980), p. 289

[7] H Shioyama. Carbon, 35 (1997), p. 1664

[8] H Shioyama. Synth. Met., 114 (2000), p. 1

[9] H Shioyama, K Tatsumi, N Iwashita, K Fujita, Y Sawada. Synth. Met., 96 (1998), p. 229

[10] H Shioyama. Mol. Cryst. Liq. Cryst., 340 (2000), p. 101

[11] I.M Panayotov, I.B Rashkov. J. Appl. Polym. Sci.: Polym. Chem. Ed, 11 (1973), p. 2615

[12] I.M Panayotov, I.V Berlinove, I.B Rashkov. J. Appl. Polym. Sci.: Polym. Chem. Ed, 13 (1975), p. 2043

[13] R Puffr, N Vladimirov. Makromol. Chem., 194 (1993), p. 1765

[14] H Podall, W.E Foster, A.P Giraitis. J. Org. Chem., 23 (1958), p. 82

[15] D.E Bergbreiter, J.M Kilough. J. Am. Chem. Soc., 100 (7) (1978), p. 2126

[16] Polymer handbook, 4th ed. New York: John Wiley \& Sons, Inc.; 1999. p. VII265-88..

[17] J.M Lalancette, R Roussel. Can. J. Chem., 54 (1976), p. 2110

[18] J.M Lalancette, R Rollin, P Dumas. Can. J. Chem., 50 (1972), p. 3058

[19] J Zhu, C.A Wilkie. Polym. Int., 49 (2000), p. 1158

[20] K Kinoshita. Carbon electrochemical and physicochemical properties. John Wiley and Sons, New York (1988) p. 108-111

[21] A Blumstein. J. Polym. Sci.: Part A, 3 (1965), p. 2653

[22] A Blumstein. J. Polym. Sci.: Part A, 3 (1965), p. 2665

[23] A Blumstein, F.W Billmeyer. J. Polym. Sci.: Part A-2, 4 (1966), p. 465

[24] A Blumstein, R Blumstein, T.H Vandersppurt. J. Colloid Interface Sci., 31 (1969), p. 236

[25] A Blumstein, S.L Malhotra, A.C Watterson. J. Polym. Sci.: Part A-2, 8 (1970), p. 1599

[26] A Blumstein, K.K Parikh, S.L Malhotra, R Blumstein. J. Polym. Sci.: Part A-2, 9 (1971), p. 1681

[27] Gilman JW, Kashiwagi T, Nyden M, Brown JET, Jackson CL, Lomakin S, In: Al-Maliaka S, Golovoy A, Wilkie CA, editors. Chemistry and technology of polymer additives. London: Blackwell Scientific; 1998. p. 249-65.

[28] J Zhu, A.B Morgan, F Lamellas, C.A Wilkie. Chem. Mater., 10 (2001), p. 3774 